\title{
Author Correction: Next-generation information to support a sustainable course for European forests
}

Gert-Jan Nabuurs (D), Peter Verweij, Michiel Van Eupen, Marta Pérez-Soba, Helga Pülzl and Kees Hendriks

Correction to: Nature Sustainability https://doi.org/10.1038/s41893-019-0374-3, published online 11 September 2019.

In the version of this Brief Communication originally published, the affiliation for Marta Pérez-Soba, 'EU Joint Research Centre, Ispra, Italy', should have been listed as her present address; her main affiliation should have been 'Wageningen Environmental Research, Wageningen, The Netherlands'; these have now been corrected.

Additionally, owing to a technical issue, the Supplementary Information file did not originally appear with this article; the file is now uploaded.

Published online: 30 September 2019

https://doi.org/10.1038/s41893-019-0410-3 